\title{
Comparison of Artificial Bee Colony Algorithm with other Algorithms used for Tracking of Maximum Power Point of Photovoltaic Arrays
}

\author{
B. Babar and A. Crăciunescu \\ Faculty of Electrical Engineering \\ University „Politehnica” of Bucharest \\ Splaiul Independenței 313, 060046 - București, Romania \\ e-mail: bilalquet@yahoo.com, aurelian.craciunescu@upb.ro,
}

\begin{abstract}
Maximum power point tracker (MPPT) is one of the key components of a solar electricity generation systems. It is used to extract the maximum power produced by an array of Photovoltaic cells. In this paper Artificial Bee Colony algorithm is analysed and implemented for tracking the maximum power point of Photovoltaic arrays. Furthermore the results obtained from $\mathrm{ABC}$ algorithm are compared with that of Perturb and Observe method, Fuzzy Logic Control and Genetic Algorithms.
\end{abstract}

\section{Key words:}

Artificial Bee Colony algorithm, Photovoltaic arrays, Maximum Power Point Tracking.

\section{Introduction}

An increase in the use of solar electric energy has been observed in recent years. The reason of this focus on photovoltaic is due of their simple structure, noiseless operations and little maintenance. More over these systems can be designed from very small power generating systems to very large Mega-Watt systems. The main drawbacks of Photovoltaic systems include lower efficiency and a high capital cost. Currently the efficiency of photovoltaic systems is in the range of $9-17 \%$. In addition to that, characteristics of photovoltaic are non-linear and mainly depend on the environmental conditions. To overcome the issues of high installation costs the efficiency of these systems has to be increased. One of the main techniques to increase PV energy harvesting is by keeping the photovoltaic to extract power at its maximum point. In Fig. $1 \mathrm{P}-\mathrm{V}$ and $\mathrm{I}-\mathrm{V}$ typical characteristic diagrams of Photovoltaic systems are shown. These characteristics are mainly dependent on the environmental conditions and the maximum power point coordinates change with the temperature and solar irradiance. In the last time, in literature are proposed different intelligent algorithms for seeking of the maximum power point [1-5]. In this work the Artificial Bee Colony algorithm used for maximum power point tracking is analysed and compared with other algorithms used for the same purpose: Perturb and Observe algorithm, Genetic Algorithm and Fuzzy Logic algorithm.

\section{Artificial Bee Colony algorithm}

The artificial bee colony algorithm (ABC) was introduced by Karaboga in 2005 [6] and a modified version was introduced in by Akay and Karaboga in 2010 [7]. In a bee swarm there is a very efficient natural task management mechanism that actively changes by the condition of the surroundings. Foraging behaviour is one of the very important parts of bee swarms. It is guided by the factors such as task management, division of labour, grouping of bees according to their statuses and the quantity and quality of the available food. The two main management criteria for the foraging are recruitment for exploring food sources and the abandonment after their depletion.

Naturally there are three groups of bees in a swarm and they differ with each other due to the tasks handled by them. Scouts bees have the job of founding new food sources; they do their job by randomly exploring the area either by internal motivation or by some external clue. Employed bees exploit the already discovered food source until the food source is depleted. Onlooker bees wait in the hives and they select a food source after getting motivated by watching dances performed by the employed bees in the dancing area. Dancing area can be considered as the main information sharing area of the bee hives. In this area the employed bees return with the nectar and perform different types of dances, while at the same time the onlooker bees watch these dances. Different types of dances are performed for example round, tremble and waggle dance. The type of dance and its intensity provides a measure of the feasibility of the food source [8].

The three groups of bees in a hive, as explained before, perform specialized task for maximizing the amount of nectar. In the algorithm, half of the bees are always 
employed bees while half of them are onlooker bees. Every food source is exploited by a single employed bee, which means for every employed bee there is one food source available. All the food sources are considered as viable solutions for a particular problem, which means, there are as many solutions as there are employed bees. The steps taken by the algorithm is explained below:

1) In the beginning the population is initialised in the range encompassing the pre-defined upper limit and the lower. All the employed bees are allocated a position in the search space, bearing a particular solution. The initialisation is performed by using the following equation:

$$
x_{i j}=x_{j}^{\min }+\operatorname{rand}(0 ; 1)\left(x_{j}^{\max }-x_{j}^{\min }\right),
$$

Where $i=1,2,3 \ldots, \mathrm{SN}$ and $\mathrm{j}=1,2,3 \ldots, \mathrm{D}$. $\mathrm{SN}$ is the population of the colony and $\mathrm{D}$ is the number of parameters to be optimised by the algorithm. After the initialisation, changes are brought in these positions until the maximum number of cycles is reached or some error criteria are met. 2) As explained earlier, each food source is associated with one employed bee, after the initialisation each employed bee is allotted a food source. After this allotment the bee makes changes the position of the food source depending on local information and explores surrounding food source. Once it finds a source it evaluates its quality. The neighbouring food sources are defined by the following equation.

$$
t_{i j}=x_{i j}+\varphi_{i j}\left(x_{i j}-x_{k j}\right)
$$

The food source $t_{i}$ in the neighbourhood of $x_{i}$ is found by changing one parameter of $x_{i}$. In the above equation $j$ is a random integer in the range of $[1, D]$ while and $k=\{1,2,3 \ldots, \mathrm{SN}\}$ is a randomly chosen index that is different than $i$. and $\varphi_{i j}$ is a randomly distributed number in the domain $[-1,+1]$. It can be seen from equation (2) that as the difference between $x_{i j}$ and $x_{j k}$ decreases an optimal value is reached. When these two values become equal, there are no more changes in the position. After finding $t_{i}$ a fitness value is assigned to each $t_{i}$ by the following equations:

$$
\text { fitness }_{i}= \begin{cases}1=(1+f i) & \text { if } f i \succ 0 \\ 1+a b s(f i) & \text { if } f i \prec 0,\end{cases}
$$

Where, $f i$ is the cost value of the solution $t_{i}$. Following that a greedy selection is applied to the values obtained for $x_{i}$ and $t_{i}$, a better value between the two is selected according to their fitness.

3) When all the employed bees have completed their searches and the first cycle is completed, the information regarding the quantity of the nectar (solution) is shared with the onlooker bees in the dancing area. An onlooker bee makes a probability on the quality of nectar (by the fitness values). In the $\mathrm{ABC}$ algorithm a roulette wheel scheme is used for such probabilistic values as shown in the equation below:

$$
P_{i}=\frac{\text { fitness }_{i}}{\sum_{i=1}^{S N} \text { fitness }_{i}},
$$

4) In such a probabilistic selection scheme, as the fitness of solutions increases, the number of onlookers attracted towards them also increases. This is the positive feedback feature of ABC. When one complete search cycle is complete, the algorithm searches for the exhausted food sources by checking the counters and comparing it with a pre-set value called the "limit". If the values are the same the food source is abandoned and a new food source is searched by the scout bees and replaced with the abandoned source. This is the negative feedback feature of $\mathrm{ABC}$.

5) The above three steps are repeated and the possible solution sets are optimized till the criteria of the maximum number of cycles is met or the pre-defined error value is reached.

By following the above steps a global minima is achieved by the algorithm.

\section{The objective function}

Swarm intelligence algorithm like Particle Swarm Optimization, ABC algorithm etc or evolution algorithms like Genetic algorithms works on minimizing an objective function. But, when we consider seeking a maximum power point in PV arrays the scenario changes. The problem becomes a maximization problem. There are two solutions for solving this problem, the first is to bring a change in the whole algorithm and change it to seek for maximization, or to bring a change in the objective function. For MPPT, the power was chosen as the objective function which is shown in the equation below:

$$
f_{\min }(I, V)=-\left\{I_{p h}-I_{D s a t}\left\{\exp \left[\frac{q\left(V+I R_{s}\right.}{a m \cdot k \cdot T}\right]-1\right\}-\frac{V+I R_{s}}{R_{p}}\right\} \cdot V,
$$

The above equation is the equation for the output power of the PV cells. The minus in the beginning of the equation changes all the produced values of power into negative values. The parameters $I$ and $V$ are varied over the range defined in the $\mathrm{ABC}$ algorithm and the solutions are fed into the algorithm and minimization process begins. In the MATLAB m-file equation (4) was written as:

$$
\begin{aligned}
& \text { ObjVal }=\left(\operatorname{Ipv}-\mathrm{Io}^{*}\left(\exp \left(\left(x 2+x 1^{*} \mathrm{Rs}\right) / \mathrm{Vt} / \mathrm{Ns} / \mathrm{a}\right)-1\right)-\right. \\
& \left(\mathrm{x} 2+x 1^{*} \mathrm{Rs}\right) / \mathrm{Rp}^{*} \mathrm{x} 2
\end{aligned}
$$

where $\mathrm{x} 1$ is the current and $\mathrm{x} 2$ is the voltage.

\section{Results and analysis}

For tracking the maximum power point, the artificial bee colony algorithm was implemented in MATLAB. For 
testing the algorithm, the Kyocera KC200GT PV panel was modelled in MATLAB. The specifications for this PV panel are given in the Table I.

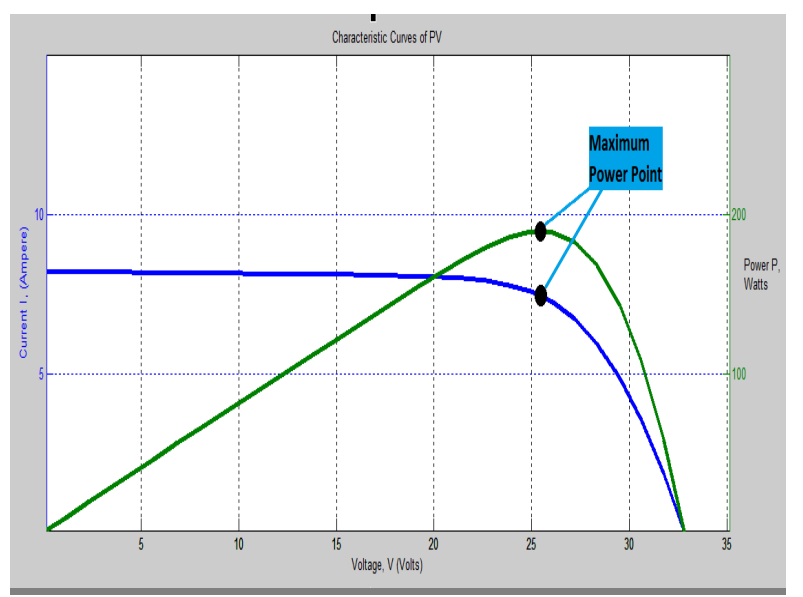

Fig. 1. Photovoltaic panel I-V and P-V characteristic curves; maximum power point is shown on these curves.

Table I. Specifications of KYOCERA KC200GT panel

\begin{tabular}{|l|c|}
\hline \multicolumn{1}{|c|}{ Variable } & Value \\
\hline Maximum Power, Pmax & 200 Watts $(+10 \% /-5 \%)$ \\
\hline Maximum Power Voltage, Vmpp & $26.3 \mathrm{~V}$ \\
\hline Maximum Power Current, Impp & $7.61 \mathrm{~A}$ \\
\hline Open Circuit Voltage, Voc & $32.9 \mathrm{~V}$ \\
\hline Short Circuit Current, Isc & $8.21 \mathrm{~A}$ \\
\hline Temperature Coefficient, KVoc & $-1.23 \times 10^{-1} \mathrm{~V} /{ }^{0} \mathrm{C}$ \\
\hline Temperature Coefficient, KIsc & $3.18 \times 10^{-3} \mathrm{~A} /{ }^{0} \mathrm{C}$ \\
\hline
\end{tabular}

The results of output power maximum searched by the Artificial Bee Colony algorithm are given in Table II. The irradiance $\mathrm{G}$ and the temperature $\mathrm{T}$ were set at $1000 \mathrm{~W} / \mathrm{m}^{2}$ and $25^{\circ} \mathrm{C}$, respectively. The simulation was performed 10 times to check the reliability of the algorithm.

Table II. ABC algorithm results for $1000 \mathrm{~W} / \mathrm{m}^{2}$ and $25^{\circ} \mathrm{C}$

\begin{tabular}{|c|c|}
\hline Run Number & Output Value of $\mathbf{P}_{\mathbf{m a x}}$ \\
\hline 1 & 206.087 \\
\hline 2 & 195.189 \\
\hline 3 & 189.110 \\
\hline 4 & 205.008 \\
\hline 5 & 199.028 \\
\hline 6 & 205.008 \\
\hline 7 & 203.606 \\
\hline 8 & 204.848 \\
\hline 9 & 205.008 \\
\hline 10 & 200.675 \\
\hline
\end{tabular}

In the above sample of outputs the best value is 206.087 , the worst value is 189.11 and the average of the above data is 201.36 which has an error of $0.0068 \%$. The average time for one run was 0.2 seconds.

Along with Artificial Bee Colony algorithm, Perturb and Observe Algorithm, Genetic Algorithm and Fuzzy Logic Algorithm were applied for the same PV panel. A comparison of Artificial Bee Colony algorithm with
Perturb and Observe algorithm, Genetic Algorithms and Fuzzy Logic algorithm is shown in Table III.

Table III. $\mathrm{P}_{\max }$ given by different algorithms

\begin{tabular}{|r|r|r|r|r|}
\hline Irradiation & \multirow{2}{*}{$\mathrm{ABC}$} & \multicolumn{1}{c|}{$\mathrm{P} \& \mathrm{O}$} & \multicolumn{1}{c|}{$\mathrm{GA}$} & $\mathrm{FL}$ \\
\hline$\left(\mathrm{W} / \mathrm{m}^{2}\right)$ & \multicolumn{1}{|c|}{$\mathrm{W}$} & \multicolumn{1}{c|}{$\mathrm{W}$} & \multicolumn{1}{c|}{$\mathrm{W}$} & \multicolumn{1}{c|}{$\mathrm{W}$} \\
\hline 1000 & 206.08 & 200.10 & 205.00 & 199.00 \\
\hline 800 & 163.61 & 160.40 & 161.17 & 157.10 \\
\hline 600 & 118.63 & 119.30 & 118.46 & 91.09 \\
\hline 400 & 71.51 & 45.55 & 75.42 & 41.31 \\
\hline 200 & 33.56 & 36.70 & 31.09 & 10.92 \\
\hline
\end{tabular}

It is worth mentioning here that for Perturb and Observe algorithm a time of 4.5 seconds was used, while for other algorithms on the average 0.3 seconds was used. The data from the Table III can be better visualized in graphic form. In Figure 2 the power correlation graph of the used algorithms is shown. It can be seen that $\mathrm{ABC}$ algorithm performs better that other algorithms.

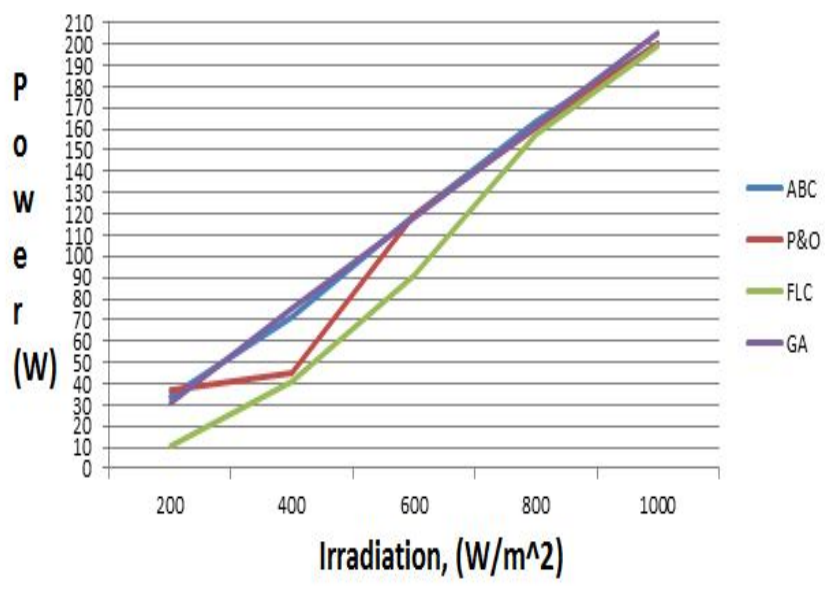

Fig. 2. Power correlation graph comparing performances of $\mathrm{ABC}, \mathrm{P} \& \mathrm{O}, \mathrm{GA}$ and FL algorithms in seeking MPP at different irradiations.

\section{Conclusion}

The Artificial Bee Colony algorithm can be considered as one of the main competitive algorithms for the maximum point tracking of the Photovoltaic arrays. In comparison with Perturb \& Observe and Fuzzy Logic algorithms, ABC Perturb \& Observe and Fuzzy Logic algorithms, $\mathrm{ABC}$ algorithm give better results. It gives similar or superior results in comparison with Genetic algorithm.

\section{Acknowledgement}

This work was realized through the Partnership program in priority domains - PN II, developed with support from ANCS CNDI - UEFISCDI, project no. PN-II-PT-PCCA2011-3.2-1670.

\section{References}

[1] S. Farhad, M. Saffar-Avval, Younessi-Sinaki, "Efficient design of feedwater heaters network in steam power plants 
using pinch technology and exergy analysis". International Journal of Energy Research, 32 (2008), pp. 1-11.

[2] UNDP. World energy assessment 2000 - energy and the challenge of sustainability. New York: UNDP; 2000 (ISBN 9211261260).

[3] S. Bilgen, K. Kaygusuz and A. Sari "Renewable energy for a clean and sustainable future Energy Sources", Part A: Recovery, Utilization, and Environmental Effects, 26 (12) (2004), pp. 1119-1129.

[4] P. Bhubaneswari, S. Iniyan, R. Goic..A review of solar photovoltaic technologies.. Renewable and Sustainable Energy Reviews, 15 (2011), pp. 1625-1636.

[5] H.L. Tsai et al, "Development of generalized photovoltaic model using MATLAB/SIMULINK". 978-988-98671-0-2. World Congress on Engineering and Computer Science, WCECS'08, San Francisco (October 22-24, 2008).

[6] D. Karaboga, An Idea Based On Honey Bee Swarm for Numerical Optimization, Technical Report TR06, Erciyes University, Engineering Faculty, Computer Engineering Department, 2005.

[7] A modified Artificial Bee Colony algorithm for realparameter optimization Original Research Article Information Sciences, Volume 192, 1 June 2012, Pages 120142 Bahriye Akay, Dervis Karaboga.

[8] V. Tereshko, Reaction-diffusion model of a honeybee colony's foraging behaviour, in: M. Schoenauer (Ed.), Parallel Problem Solving from Nature VI, Lecture Notes in Computer Science, vol. 1917, Springer-Verlag, Berlin, 2000, pp. 807-816.

[9] http://www.kyocerasolar.com/assets/001/5195.pdf

[10] J.C.H. Phang, D.S.H. Chan and J.R. Phillips, "Accurate analytical method for the extraction of solar cell model parameters". Electronics Letters, Volume 20, Issue 10, 10 May 1984, p. 406 - 408, DOI: 10.1049/el:19840281.

[11] Maximum photovoltaic power tracking for the PV array using the fractional-order incremental conductance method Original Research Article Applied Energy, Volume 88, Issue 12, December 2011, Pages 4840-4847

[12] Chia-Hung Lin, Cong-Hui Huang, Yi-Chun Du, Jian-Liung Chen. "Maximum power tracking for photovoltaic power system: Development and experimental comparison of two algorithms". Renewable Energy, Volume 35, Issue 10, October 2010, Pages 2381-2387 Issam Houssamo, Fabrice Locment, Manuela Sechilariu.
[13] Won CY, Kim DH, Kim SC, Kim WS, Kim HS. "A new maximum power point tracker of photovoltaic arrays using fuzzy controller". In: Proceedings of 25th annual IEEE power electronics specialists conference; 1994. p. 396403.

[14] Veerachary M, Senjyu T, Uezato K." Neural-networkbased maximum-power-point tracking of coupled-inductor interleaved- boostconverter-supplied PVsystem using fuzzy controller". IEEE Transactions on Industrial Electronics 2003;50(4):749-58

[15] Yacine Labbi and Djilani Ben Attous" Maximum Photovoltaic Power Tracking under Different Conditions Using a Genetic Algorithm and Particle Swarm Optimization". Journal of Electrical and Control Engineering. ISSN 2226-2881 (Print) ISSN 2226-289X (Online)

[16] Yusof, Y.; Sayuti, S.H.; Abdul Latif, M.; Wanik, M.Z.C. Modeling and simulation of maximum power point tracker for photovoltaic system. In Proceedings of Power and Energy Conference, Kuala Lumpur, Malaysia, 29-30 November 2004; pp. 88-93.

[17] Youngseok J, et al. "Improved perturbation and observation method (IP\&O) of MPPT control for photovoltaic power systems". In: Proceedings of 31st IEEE photovoltaic specialists conference; 2005.16]

[18] Timothy, J. Ross. Fuzzy Logic with Engineering Applications, second ed. John Wiley \& Sons Ltd., 2004.

[19] F. Chekired, C. Larbes, D. Rekioua and F. Haddad, "Implementation of a MPPT fuzzy controller for photovoltaic systems on FPGA circuit". 1876-6102. 2011, Elsevier Ltd. doi:10.1016/j.egypro.2011.05.062.

[20] R. Ramaprabha and B.L. Mathur, "Genetic Algorithm Based Maximum Power Point Tracking for Partially Shaded Solar Photovoltaic Array". International Journal of Research and Reviews in Information Sciences (IJRRIS) Vol. 2, No. 1, March 2012, ISSN: 2046-6439. 